\title{
Difference in Anxiety between Left and Right Hemispheric Lesions of Ischemic among Patients with Stroke at Dr. Moewardi Hospital
}

\author{
M. Maulana Shofri'1), O. S. Hartanto²), Bhisma Murti3) \\ 1) Faculty of Medicine, Sebelas Maret University, Surakarta \\ 2) Neurology Department Dr. Moewardi Hospital, Surakarta \\ 3) Masters Program of Public Health, Sebelas Maret University, Surakarta
}

\begin{abstract}
Background: The difference of lesion location and anxiety usually manifests into different signs and symptomps based on the patient's lesion location. This study aimed to determine the difference in anxiety between left and right hemispheric lesions of ischemic among patients with stroke.

Subjects and Method: This was an analytic observational study with cross sectional design. A total sample of 30 patients with stroke consisting of 15 patients with left hemisphere lesion and 15 patients with right hemisphere lesion of ischemia was selected by random sampling. Anxiety was assessed using Hamilton Rating Scale for Anxiety (HRSA) questionnaire. The data were analyzed by multiple linear regression.

Results: After controlling for family supports as confounding factor, this study showed significantly lower anxiety in patients with left hemispheric lesion ischemia than patients right hemispheric lesion $(b=-2.77 ; p=0.039)$. Family support lessened anxiety among patients with stroke $(b=-5.21 ; p=0.003)$.

Conclusion: Anxiety in stroke patients with left hemispheric lesion of ischemia is lower than stroke patients with right hemispheric lesion.
\end{abstract}

Keywords: anxiety, ischemic stroke, left hemispheric lesion, right hemispheric lesion

Correspondence:

M. Maulana Shofri. Faculty of Medicine, Sebelas Maret University, Surakarta.

\section{BACKGROUND}

$\overline{\text { Stroke is a clinical syndrome including dis- }}$ turbance in cerebral function that occur during 24 hours or more which cause death or permanent disability, and without any other apparent vascular disorders (WHO, 2006). Stroke can be divided into two types: ischemic stroke and hemorrhagic stroke. An ischemic stroke is usually caused by acute vascular occlusion, can sometime be caused by focal artery stenosis and combined with reduced perfusion pressure or collateral flow (Lumbantobing, 2011).

Stroke is the third leading cause of death in the world (Bousser, 2008). Eighty percent of stroke are caused by cerebral ischemia (Worp and Gijn, 2007). According to the World Health Organization (WHO), approximately 5.71 million people died from stroke in 2004 and this figure was expected to rise to 6.3 million by 2015 (Juan et al., 2010). In Asia, incidence of stroke ranges from 50-400 people per 100,000 populations per year (Bethesda Stroke Center, 2007). In Indonesia, stroke causes approximately $15.4 \%$ of all deaths (Kusuma et al., 2009). Stroke ranks first in the number of patients hospitalized at the Department of Neurology (Aliah et al., 2007). After the age 55 years the incidence of stroke increases twice as many in men than women. A study reported that $75-89 \%$ of stroke occur in people over 65 years. Fifty percent of stroke occurs in individuals aged over 70 years and almost $25 \%$ occurs in individuals aged over 85 years (Feigin et al., 2003). 
Stroke is the major cause of physical, cognitive, perceptual, and emotional disability, as well as disturbance of social life in adults (Nusantara Medical Center, 2009; Tarasova et al., 2007). Thirty to sixty percent of patients with stroke who survive are dependent on others in daily activities (Duncan, 2000). Stroke causes many problems to patients and their family, including loss of confidence, depression, anxiety, decrease in work productivity, disrupted marital relationship. These problems may disrupt patient role in the family and community (Toole, 2000). The changes in physical, cognitive, and psychosocial integrity manifest in anxiety, frustration, and depression (Robinson, 1997).

Anxiety is an unpleasant emotional state and subjective feelings that include tension, fear, and anxiety (Trismiati, 2004). The patients show fear going out of the house and embarrassment to meet other people(Thomas, 1993). The complication of anxiety and depression are observable in stroke patients (Bruggimann et al., 2006; Fure et al., 2006). Anxiety occurs after stroke with prevalence between 6-13\% (Robinson, 1987). Anxiety prevalence increases to $17 \%-50 \%$, if there is also depression (Opara and Jaracz, 2010).

Based on this background, the researcher conducted a study on the relationship between anxiety and location of the lesion in patients with ischemic stroke.

\section{SUBJECTS AND METHOD}

This study was an observational analytic study with cross sectional design. The study was conducted at the Neurology Clinic Outpatients at Dr. Moewardi Hospital, Surakarta. Subjects were patients with neurological outpatient clinic Dr. Moewardi Hospital, Surakarta with some inclusion and exclusion criteria. Sampling technique was using exhaustive sampling of 30 patients.
Variables examined included: Location ischemic stroke lesions consisting of a left and right hemisphere lesion as independent variables and the anxiety as the dependent variable. The diagnosis of lesion location obtained through physical examination by experts neologies to see the clinical manifestations and CT-Scan photos. Lesions in one hemisphere will lead hemiparesis on contralateral. Anxiety scale measured by Hamilton Rating Scale for Anxiety (HRSA) (Nursalam, 2003). It determined the extent of a person's degree of anxiety whether mild, moderate, severe or very severe. Consists of 14 groups specify into each elaborated symptoms that are more specific (Hawari, 2008).

Scale score data related to the anxiety is a numerical scale. This study also controlled for confounding the family support variables. Family support was assessed using a questionnaire consisting of 5 family supports sub-variable (Smet, 2004): emotional support, instrumental support, information support, esteem support, and social networking support. The instruments of the study were using the status of patient records and the results of the patients CTScan.

The information was obtained from a Medical Outcomes Study SF-36 questionnaire. The data analyzed using SPSS for Windows 17. Anxiety level between left and right hemisphere lesion was analyzed with multiple linier regression analysis, with controlling the family support shown by multiple linier regression as follows:

$$
\mathrm{Y}=\mathrm{a}+\mathrm{b} 1 \mathrm{X} 1+\mathrm{b} 2 \mathrm{X} 2
$$

$\mathrm{X} 1$ = layout hemisphere lesion (o: right; 1 : left)

X2 = Family Support (o: weak; 1 : high)

$\mathrm{a}=$ Constant

$\mathrm{b}=$ regression coefficient

The differences between the groups with a significance level of right and left he- 
misphere lesion indicated by regression coefficient b. Statistical significance was tested with the regression coefficient $\mathrm{b} t$ test. Statistical significance is indicated by the value of $p$. Interpretation of the regression coefficient $\mathrm{b}$ is as follows:

$\mathrm{b}=\mathrm{O} \longrightarrow$ no difference

$\mathrm{b}<\mathrm{O} \longrightarrow$ right lesion hemisphere is more anxiety from the left lesion

$\mathrm{b}>\mathrm{O} \longrightarrow$ left lesion hemisphere is more anxious

\section{RESULTS}

Research had been conducted in the Outpatient Neurology Clinic at Dr. Moewardi hospital, Surakarta on October 1 to November 30 in 2013. The subjects of the study were 30 people, comprising 15 subjects with ischemic stroke in the left hemisphere lesions and 15 subjects with ischemic stroke lesions of the right hemisphere. The data were collected by interview and using medical records of the patient's.

1. Age

Table 1. Stroke patient's aged

\begin{tabular}{lccccc}
\hline Variable & $\mathbf{n}$ & Minimum & Maximum & Mean & Std. Deviation \\
\hline Age & 30 & 50 & 71 & 60.90 & 5.915 \\
\hline
\end{tabular}

The results of the study subjects's minimum age is 50 years, maximum 71 years while the average age of respondents was 70 years and a standard deviation of $5915(60.90 \pm 5.915)$.

\section{Gender of Stroke Patients}

The table shows the male sex more by 16 people (53.3\%) than women by 14 people (46.7\%).

Table 2. Gender of stroke patients distribution

\begin{tabular}{lcccc}
\hline Varible & n & Frequency & Valid Percent & $\begin{array}{c}\text { Cumulative } \\
\text { Percent }\end{array}$ \\
\hline Female & 14 & 46.7 & 46.7 & 46.7 \\
Male & 16 & 53.3 & 53.3 & 100.0 \\
Total & 30 & 100.0 & 100.0 & \\
\hline
\end{tabular}

\section{Education}

The subject study's education is elementary at 18 people $(60 \%)$ of respondents JSE fol- lowed by 8 people (26.7\%) and respondents who had high school for 4 people (13.3\%).

Table 3. Results of chi square test support family relationships with anxiety

\begin{tabular}{lccccccc}
\hline \multirow{2}{*}{$\begin{array}{c}\text { Family } \\
\text { Support }\end{array}$} & \multicolumn{9}{c}{ Mild } & \multicolumn{2}{c}{ Anxiety } & \multirow{2}{c}{ Medium } & \multicolumn{2}{c}{ Severe } & \multirow{2}{*}{ p } \\
\cline { 2 - 6 } & $\mathbf{n}$ & $\mathbf{\%}$ & $\mathbf{N}$ & $\mathbf{\%}$ & $\mathbf{n}$ & $\%$ & \\
\hline Non Suportif & $\mathrm{O}$ & $\mathrm{O}$ & 3 & $10 \%$ & 3 & $(10 \%)$ & 0.027 \\
Suportif & $\mathbf{1 1}$ & 36.7 & 11 & $36.7 \%$ & 2 & $(6.7 \%)$ & \\
Total & 11 & 36.7 & 14 & $46.7 \%$ & 5 & $(16.7 \%)$ & \\
\hline
\end{tabular}


Shofri et al./ Difference in Anxiety between Left and Right Hemispheric Lesions

4. Anxiety of Family Support Relationship

Table 4. Results of the chi square relations hemisphere lesions layout with anxiety

\begin{tabular}{|c|c|c|c|c|c|}
\hline \multirow{2}{*}{$\begin{array}{c}\text { The lesion } \\
\text { Hemisphere }\end{array}$} & \multicolumn{3}{|c|}{ Anxiety } & \multirow{2}{*}{ Total } & \multirow[b]{2}{*}{$\mathbf{p}$} \\
\hline & Mild & Medium & Severe & & \\
\hline Right & $4(13.3 \%)$ & 6 (20.0\%) & $5(16.7 \%)$ & $15(50.0 \%)$ & 0.047 \\
\hline Left & $7(33.3 \%)$ & $8(26.7 \%)$ & o (0.0\%) & $15(50.0 \%)$ & \\
\hline Total & 11 (36.7\%) & $14(46.7 \%)$ & $5(16.7 \%)$ & $30(100 \%)$ & \\
\hline
\end{tabular}

The Table 4 shows the overall family support is supportive of the patient's anxiety that is $80 \%$ larger than non-supportive

which is $20 \%$, and significant relationship $(\mathrm{p}=0.027)$ between family support with anxiety.

5. Relationship with Anxiety Hemisphere Lesions Layout

Table 5. Test results multiple regression analysis

\begin{tabular}{lccccc}
\hline \multirow{2}{*}{ Variable } & \multicolumn{2}{c}{$\begin{array}{c}\text { Unstandardized } \\
\text { Coefficients }\end{array}$} & $\begin{array}{c}\text { Standardized } \\
\text { Coefficients }\end{array}$ & t & p \\
\cline { 2 - 4 } & $\mathbf{B}$ & Std. Error & Beta & & \\
\hline (Constant) & 28.424 & 1.474 & & 19.285 & 0.000 \\
Hemisphere & -2.771 & 1.280 & -.327 & -2.166 & 0.039 \\
Lesion & -5.214 & 1.600 & -.492 & -3.259 & 0.003 \\
Family Support & & & & & \\
\hline
\end{tabular}

Anxiety level differences between left and right hemisphere lesion was analyzed with multiple linear regression analysis, with control of the influence of family support, demonstrated by multiple linear regressions as follows:

According to the table above multiple regression analysis test $t$ variable layout hemisphere lesions of 2166 and $\mathrm{p}=0.039$, these regression suggest that there is a significant difference lies hemispheric lesions to anxiety patients with stroke. While the negative sign on the regression coefficient ( $\beta=-2771)$, it indicates that the left hemisphere lesions had lower anxiety of the right hemisphere lesion.

Variable family support have significant differences, it can be seen on the $t$ amounted to 3.259 and $\mathrm{p}=0.003$. The regression coefficient $\beta=-5.214$, showed that the higher the family support the lower anxiety in people with stroke.

\section{DISCUSSION}

Age restricted subjects between the ages of 50-71 years old with an average age of respondents was 60.90 because according Coonley (2006) anxiety that occurs with age-related stroke patients. Thus the researchers took samples of the inclusion criteria ischemic stroke patients with age> 50 years as age increases the incidence of anxiety is increasing, coupled with the support of the family is less support on stroke patients to perform daily activities.

Results gender distribution of patients with stroke. The big difference in the percentage of subject men and women in the study cannot prove whether gender influenced the incidence of stroke. This is because this study applies certain criteria in 
sampling the subject of research, so it does not include all stroke patients who met the study time period.

In stroke patients as most of the respondents have a supportive family support than the non-supportive. Family support is a variable outside of the dependent and independent variables that need to be controlled because it can affect the level of anxiety in addition to lesions that occur in the brain. The better support the lower levels of anxiety.

In the study Robinson (2006) explains that the left hemisphere lesion causes a decrease in the biogenic without compensation elevation of serotonin regulation as a result of depression may appear. While the right hemisphere lesion causes the elevation of serotonin regulation (due to compensatory mechanisms) that can cause anxiety. In some studies right hemisphere lesion was significantly correlated with the incidence of anxiety or anxiety (Astrom, 1996; Erhan et al., 200o; Ghika et al., 1997).

From the data and some of the research that has been done there are differences in the incidence of anxiety in lesions of the right hemisphere than the left. Due to an increase in serotonin and compensation occurs in the right hemisphere tends to lead to people anxious than patients with lesions of the left hemisphere lesions occur e.g. depletion that leads to depression.

This study has a weakness in terms of the number of samples which amounted to only 30 people. Although the sample size was determined based mechanisms are valid, it seems unable to give real picture of the disease in the community. Besides this, there are many factors that can confuse the results of which fall in external variables uncontrollable because of space constraints such as the degree of weakness/ paralysis of limbs, physical stressors, psychosocial stres- sors, anxiety-related treatment that affected the results.

Based on the research that has been done can be concluded that there is a significant difference between anxiety ischemic stroke patients left and right hemisphere lesion. Genesis anxieties are more prevalent in patients with lesions of the right hemisphere ischemic stroke than patients with ischemic stroke in the left hemisphere lesion.

Management of stroke should consider anxiety so as to obtain the appropriate therapy and can determine with good prognosis. Exclude other variables that also affect the location of the stroke lesion on the incidence of anxiety.

\section{REFFERENCE}

Aliah A, Kuswara FF, Limoa RA, Wuysang G (2007). General overview of brain blood circulation Disorders (GPDO). In: Harsono 2nd edition: Capita Selecta Neurology. Yogyakarta: Gadjah Mada University Press 81-102.

Astrom M, Asplund K (2005). Handicap and quality of life after stroke. In: Bogousslavsky $J$ (ed). Long term effects of stroke. New York: Marcel Dekker, Inc 25-48.

Bethesda Stroke Center (2007). Six Steps Handling Stroke. http optimal handling://www.Strokebethesda.comconte nt/view/152/42/. Accessed January 2013.

Bousser MG (2008). Relation between migraine and stroke. The Lancet Neurology 4: 533-542.

Bruggimann L, annoni JM, Staub F, von Steinbu"chel N, Van der Linden M, Bogousslavsky J(2006). Chronic Posttraumatic Stress Symptoms after stroke no severe. Neurology, 66, 513-516. doi: 10.1212/o1.wnl.ooo0194210.987 57.49 
Coonley T (2006). Breaking Free from the Anxiety Trap. http://www.wshg.org. uk. Accessed January 2013.

Duncan (2000). Prognostic value of blood pressure when the patient entered the hospital in pain in patients with acute infarction stroke.

Erhan H, Ochâo E, Borod J, Feinberg T (2000). Consequences of right cerebrovasculer accident on emotional functioning: diagnostic and treatment implication. CNS Spectr 5(3): 25-38.

Feigin VL, Lawes CM, Bennett DA, Anderson CS (2003). Stroke epidemiology: A review of population-based studies of the incidence, prevalence, and casefatality in the late 2oth century. Lancet Neurology 2: 43-53.

Hawari D (2006). Management of Stress, Anxiety, and Depression. Jakarta: Balai FKUI Publishers 130-132.

Kusuma Y, Venketasubramanian N, Kiemas LS, Misbach J (2009). Burden of stroke in Indonesia. International Journal of Stroke 4(5): 379-380.

Juan de JL, Adolfo V, Otman F, Juan CL, Rudbeskia P, Ana ML, Beatriz M (2010). Prevalence of stroke and associated risk factors in older adults in the city and Matanzas provinces havana, cuba (10/66 populationbased study). MEDICC Review 12(3): 20-26.

Lumbantobing SM (2011). Stroke. In: Neurogeriatri. Jakarta: FK UI Hall Publishers 93-134.

Nusantara Medical Center (2009). Stroke attack otak.http://www.nusantaramc.com/highlights_detail.php?Id=6. Accessed February 2013.
Opara JA, Jaracz K (2010). quality of life of post-stroke Patients and their caregivers. Journal of Medicine and Life 3(3): 216-220.

Robinson RG, Starr LB, Kubos KL (2006). A two-year longitudinal study of poststroke mood disorder: findings during the initial evaluation. stroke; Journal of the American Heart Association 14: 736-741.

Smet KG (2004). Social support survey. Journal of social science and Medicine 32: 705-706.

Tarasova M, Nečasová J, Mikulík R, Pohanka M, Hashim MKA, Drliková L, Bartlova B (2007). Quality of Life in Patients after acute stroke.Scripta Medica (BRNO) 8o(5): 243-252.

Trismiati (2004). Anxiety level differences between male and female contraception acceptor steady at Hospital Dr. Sardjito. Journal Psyche 1(1).

Toole (2000). Prognostic value of blood pressure when the patient was hospitalized in acute infarction stroke. B.NeuroSains 1(3): 161-162.

World Health Organization (2006).The WHO stepwise approach to stroke surveillance.

Worp HB, Gijn J (2007). Acute ischemic stroke. N Engl J Med 357: 572-579. 